\title{
Major Effects of Human Rights Abuses on the Academic Performance of Pupils in a Ghanaian Basic School
}

\author{
Stephen Amegadzi \\ Ghana Education Service, New Winneba M/A Basic School, Box 54, Winneba, Central Region, Ghana
}

\begin{abstract}
The findings and results showed that several abuses occur in the school. The findings suggest that the majority of teachers and students have knowledge of the rights of the children in school. They believe that students have right to participate in school decision making, protection against sexual harassment and verbal abuse, and protection from torture or inhumane treatment. However, there were several violations - verbal assault, sexual harassment, emotional violence, non-participation in decision making and public humiliation of students are very prevalent in the school. Both teachers and students perpetrate human rights violations. Due to violations, some students do not recognize that they have rights such as religious rights, freedom of expression and pedagogic rights.
\end{abstract}

Keywords: Human Rights, Abuse and Effects

DOI: $10.7176 /$ ISDE/11-1-01

Publication date: January $31^{\text {st }} 2020$

\subsection{Introduction}

There are several concerns about human rights abuses especially in schools and must be condemned by all. The fact that a person enrolls in junior high school does not in any way curtail his or her fundamental human rights. Pupils do all kinds of work ranging from house cleaning, feeding the children of their teachers, farming, and cooking among others for their teachers. They perform difficult household chores for teachers while living in the school. Sex for marks is perceived to be widespread in junior high schools in Ghana of which the Gomoa East District is not an exception. There is a perception that scoring high marks at school has very little to do with how clever or hard-working pupils are. Some pupils serve as wives for their teachers for marks, favours and money, preventing them from achieving the purpose for which they were sent to school.

Human right abuses such as these affect the child's development both physically and psychologically. In fact, the world risks losing young and fresh minds who may be the leaders of the next generation if the rights of pupils are not protected at school. Children have a right to be free from economic exploitation and sexual abuse. They have right to go to school and enjoy freedom from trafficking for forced labour among others. If these children are not protected it is very unlikely that they will enjoy these rights to the fullest.

\subsection{Statement of the Problem}

This research is concerned that abuse of pupils can have a wide range of psychological effects. The short-term impact can include symptoms such as panic, lack of concentration, fairness and anger. Long-term consequences that may occur include psychological problems such as anxiety or depression, psychosomatic symptoms such as unexplainable illnesses, suicide, delinquency, and further victimization.

\subsection{Purpose of the Study}

The purpose of this study is to examine the abuse of pupils' rights in junior high schools in Gomoa Abonyi Basic School in the Gomoa East District of Ghana. The study therefore obtained the views of pupils and teachers on the human rights abuses that occur in junior high schools.

\subsection{Objectives of the Study}

The specific objectives that guided the study were to:

- identify the forms of forms of Human rights abuses in the study schools.

- identify the factors that contribute to human rights abuses in the study schools.

- $\quad$ examine the effects of human rights abuses on pupils.

- Analyse ways of reducing human rights abuses in the study Schools.

\subsection{Research Questions}

The following research questions guided the study:

- What are the psychological effects of human rights abuse on pupils in the study area?

- What are the effects of human rights abuse on the academic performance of pupils in the study area?

- What are the physical effects of human rights abuse on the pupils in the study area? 


\subsection{Literature Review}

A research conducted by 'Plan Ghana' a Non-Governmental Organization (NGO) in Ghana in 2006 revealed that, in most primary and secondary schools, children have no choice - they either work for the teacher or are beaten. In basic schools, working for the teachers becomes interwoven with the trade for marks.

However, Article 2.2(e), of the Forced Labour Convention gives a classic exemption to this rule. It states that minor communal service of a kind which, being performed by the members of the community in the direct interest of the said community is considered as normal civic obligations. This may include ground work at schools.

\subsection{Effects of Rights Abuses on Pupils}

Human rights abuses leave unfavourable impacts on victims. Some of these impacts are able to mart he wellbeing of a person and leave them in perpetual pain and fear. Below are literatures on the impact of human rights abuses on a child.

\subsection{Halt physical, Spiritual, Moral and Social development}

The convention on the Rights of the Child (CRC) prohibits economic exploitation and employment of children in work that is likely to be hazardous, interfere with their education, or be harmful to their education, or be harmful to their health or development. Some work children do at school ranks among the worst forms of child labour, as identified in International Labour Organization (ILO) Convention (No. 182).

Under this convention, children under the age of eighteen may not be engaged in work, which is likely to harm their health, safety, or morals. Prohibited labour includes work that exposes them to physical, psychological, or sexual abuse, forces them to work for long hours or during the night; or unreasonably confines them to their employers' premises.

Article 29 of the ACRWC is similar to article 35 of the CRC. They both deal with the sale, trafficking and abduction of children. The charter contains a specific article on child labour and provides that: 'Every child shall be protected from all forms of economic exploitation and from performing any work that is likely to be hazardous or to interfere with the child's physical, mental, spiritual, moral or social development'. There is little doubt that most of the work that children do at school could be hazardous or interfere with his or her physical, mental, spiritual, moral, or social development.

\subsection{Humiliate and Degrade Pupils}

Article 1 of Committee Against Torture (CAT) defines torture as any act committed by a public official or other person acting in an official capacity or at the instigation of or with the consent of such a person by which severe physical or mental pain or suffering is intentionally inflicted on a person for a specific purpose, such as extortion of information or confession, punishment, intimidation or discrimination. This definition shows that severe caning in schools is torture. "torture is intended to humiliate, offend and degrade a human being and turn him or her into a 'thing' (Bandura, 1977, p. 24).

As articulated in the United Nations Convention on the Rights of the Child (CRC) which was ratified by Ghana in 1990 and the chidren's Act of 1998 (Act 560), children in Ghana have a right to education and should be free from being subjected to harmful or degrading punishment and any type of abusive or exploitative labour that shall deny the child of his/her right to education. Teachers, as duty bearers and members of Ghana Education Service have a responsibility to uphold and protect children's rights (Ghana: GES, 2008).

\subsection{Damage Pupils Self-Esteem}

Nansel (2001) explained that, a child comes to know himself through the things they can do. If a teacher calls a school child names that are hurtful, if they yell at the child and tell them they cannot do anything right when they fail an examination or make a mistake, it affect the child's self-esteem. Even if the teacher occasionally offers some praise to their pupils, it leaves the school child astonished and confused because they are unsure of the teacher's behavior.

Verbal abuse can be highly dangerous because it leaves no bruises on the child. Instead, the bruises are left on the child's self-esteem. It is a slow form of abuse, yet very detrimental to the school child (Bandura, 1977). Some of these insults ruin on pupils by adults turn to be fulfilled in the life of the pupil. Labelling a person can affect an individual's self-conceptions. Sociological theories of interaction have long held that we see ourselves as others see us. If others see us as deviants, we may come to accept their judgment (Lawrence, 1998).

\subsection{Early Dropout of School}

In research carried out by save the Children, an NGO in 2006, sexual abuse was one of the most frequently cited reasons for early drop out, alongside gender discrimination and poverty. The same source states: Even less severe forms of sexual advancement could damage a child's education. The sexual harassment and abuse of girls in school by their teachers and other pupils is perceived to be common in Ghana. If a teacher, with unique power to 
advance a pupils interests or ruin her hopes, puts sexual pressure on a girl in his class, very few of them can resist.

The findings of a study conducted by Hazler (2000), found that boys who are sexually abused tended to have more suicide attempts, abusive acts, alcohol and other drug abuse, and run away from home more often than sexually abused girls. In general, younger children experiencing child sexual abuse tend to be a greater risk for long-term emotional and social problems. The school girl may become pregnant after sexual abuse or rape by a teacher or a fellow pupil. This may also spread HIV and AIDS through their sexual activities with a pupil or an adult. This may force the pupil out of school (Schwartz et al, 2002).

\subsection{Poor Academic Performance}

Of particular concern has been the proof that frequent bullying among children has negative impact on victim's school achievement. This issue has been examined through a large scale study of bullying in USA by Nansel, et al (2000). They found from the observation of 15,000 pupils in grade $6-10$ that there is a significant association between bullying involvement and lower self-perceived academic achievement. In addition to this, Schwartz et al (2002), notes that those who are frequently involved in abusing others show poor academic performance in school.

A healthy mind lies in a healthy body. According to World Health Organization (WHO), health is a state of complete physical, mental and social wellbeing and not merely the absence of disease or infirmity. The right to health is therefore an inclusive right that not only relates to personal physical health, but also overlaps with many other human rights and various human rights issues. This therefore explains that when a child's right to health is abused, it has a direct effect on his studies.

In the Convention on the Rights of the Child (1990), two articles address the issue of nutrition. Article 24 says that 'States Parties recognize the right of the child to the enjoyment of the highest attainable standard of health .... (paragraph 1)" and shall take appropriate measures to combat disease and malnutrition through the provision of adequate nutritious foods, clean drinking water, and health care. Some abuses in schools make pupils perform very poorly academically.

\subsection{Frequent Sickness}

Child right abuse affects children of all gender, ages, cultures and from all socioeconomic backgrounds Hazler (2000). Basic School Pupils, because of their age, if they are made to do certain type of work, if affects their health.

Children are susceptible to both physical and psychological harm and may undertake jobs that are inappropriate to their age and physical strength, for example, carrying heavy buckets of water, bamboo and firewood.

When working in the kitchen, children may be exposed to toxic cleaning chemicals, boiling liquids, extreme heat or cold. They may have to operate equipment they are not equipped to handle, as well as sharp knives, woodcutting implements or other tools inappropriate for a child (ILO, 2008). These words may affect the health of the child or render him vulnerable to health problems.

\subsection{Fear and Insecurity}

According to Farrington (1993), pupils whose rights are always abused become fearful and insecure. The right to privacy protects individual autonomy and entitles individuals to isolate themselves from their fellow human being and withdraw from public life into their own private spheres in order to shape their own lives according to their personal wishes and expectations. Certain institutional guarantees, such as protection of home, family, marriage and the secrecy of correspondence support this aspect of the right to privacy.

If the right to privacy is not respected, children become fearful. Children who are often beaten and scolded tend to miss school more often because of fear and illness. These children also have a much higher rate of accidents than do other children and they are twice as likely to have impaired vision and hearing, iron deficiency anemia, and higher than normal levels of lead in the blood, which can impair brain function (Hazler, 2000).

Perpetrators of human rights abuse on pupils use a variety of tactics to prevent their victims from unveiling them. One tactic used by perpetrators of all ages is known as desensitization (Rigby, 2003). Desensitization is where the perpetrator displays caring and compassion towards the child to get closer after the abuse. A second tactic is the use of threats. Juveniles tend to use more threats than adults. Perpetrators who victimize family members generally use their relationship with the victim to prevent disclosure. Also, perpetrators of right abuses say they search for and abuse children who they think will keep the mistreatment to themselves (Olweus, 1991).

\subsection{Uncertain Future}

An adequate and appropriate education is globally recognized as a prerequisite to earning a livelihood, breaking out of the poverty cycle and building a more secure future. Sadly, however, research shows clearly that children whose rights are abused rarely have access to any form of quality education and have often left education early in order to work, or indeed may never have been sent to school at all. The lack of opportunity to gain good education 
causes poverty among people. It is true that the more education that people have, the greater their flexibility about future career choices (Rigby, 2003).

\subsection{Further Victimization}

According to Hazler (2000), the empirical foundation of cultural transmission theory begins with the early research of Clifford Shaw and his associates (1929). They found that even though several different ethnic groups had inhibited certain Chicago neighborhoods over a period of time, the crime rate in those neighborhoods remain high. This persistence, they concluded, meant that deviance had become a part of the neighborhood's local culture. As different people moved into the area, new arrivals learned the culture of deviance from older residence. After the new residents have been there for a time, they become the established group and then pass on the culture of deviance to the next arrivals. This means as pupils are abused, they grow to become abusers of other people's rights.

\subsection{Effect on Millennium Development Goals}

The Millennium Declaration of September 2000 has united member states of the United Nations around common goals to significantly reduce poverty and misery by 2015. According to aspects of the Millennium Declaration (2000), member state must spare no effort, to free men, women and children from the abject and dehumanizing conditions of extreme poverty, to which more than a billion of them are currently subjected. Abuse of the rights of students will fight against attaining the millennium development goals because it will increase the poverty levels as they drop out of school.

\subsection{Possible consequences for those who Abuse Others}

Within studies of bullying and sexual abuse, few findings have focused on the consequences for those who perpetuate the abuse. There is no clear consensus, unlike the consequences for victims, which can enlighten us on how bullies experience the consequences of what they have been doing, upon themselves. However, there have been findings that show some possible negative consequences for those who bully (Farrington, 1993).

Olweus (2003) found out during his studies in Norwegian schools that those who had been identified as bullies in school were four times more likely to come before the low court as a consequence of delinquency. It has also been shown that those who had been identified as abusers at school were more likely than others to have children who behave aggressively. There is no clear explanation of how this happened, whether by family influence or genetic transmission or both (Rigby, 2003).

\subsection{School Right Abuse Prevention Programs}

School sexual abuse prevention programs started in the late 1970s (Kohl, 1993, as cited in Roberts and Miltenberger, 1999). Current sexual abuse prevention programs vary greatly in how they are implemented from school district to school district. In general, prevention programs teach children how to say to if a person touches them inappropriately, to leave the situation, and to tell an adult about what happened (Olweus, 1991).

One study of prevention programs in 100 Texas elementary schools found less than half of the schools offered separate prevention programs, most of the surveyed schools incorporated prevention efforts into guidance and health curriculum or did it as needed. Overall, $88 \%$ of elementary schools in United States provide right abuse prevention to pupil (Ko and Cosden, 2001).

\subsection{METHODOLOGY}

\subsection{Research Design}

The research was designed as a case study. A case study is one of several ways of doing research in any field. It is an intensive study of a single group, incident, or community. According to Reid (1994), a case study is an investigative study conducted by an individual or a group of people on a single instance or event. This was chosen because it has an advantage of producing accurate responses from a wide range of people.

Since this study mainly investigated the phenomenon of human rights abuse in school, the researcher decided to choose my participants from Gomoa Abonyi basic schools in the town where the researcher resides. In addition, the researcher decided to include teachers in this study, in order to enable them to provided additional information about their perceptions and judgments regarding human rights abuses and preferred ways of dealing with it.

\subsection{Research Population}

The design began with the identification of the population. Fortunately, the schools headteacher that the researcher contacted had no problems with the procedures if the researcher had a formal letter from the University of Education, Winneba that recommended me to do the research. In the end, I was allowed by the headteacher to take samples from the school. During the interviews with pupils, only those who were identified as abusers and those who have been abused were used as informants. There were thirty two pupils from the school who participated in 
this preliminary session to help frame the questionnaire for the study. Teachers who had been selected to become the next key informants were also based on returned consents.

\subsection{Sample Size}

The school authorities allowed me to take a sample from JHS 1, JHS 2 and JHS3. The population consisted of 44 adolescents 164 pupils representing about $45 \%$ of the target population and 10 teachers from the same schools. Bell (2004), suggested that, between 10 to 20 percent of the targeted population could make a good sample size of descriptive research. All participants were drawn from Gomoa Abonyi basic school located in the Gomoa East District, Central Region.

\subsection{Sampling Procedure}

A purposive sampling method was used to select a school where 44 students and 10 teachers were selected. The population was considered reasonable based on budget and time considerations (Donkor, 1996). The population consisted of only pupils and teachers in Gomoa-Abonyi Basic School in the Gomoa East District. After this, random sampling was used to select the respondents (pupils and teachers) from the schools chosen to be the respondents. The teachers included five female teachers and five male teachers of Gomoa Abonyi Basic School.

\subsection{Instruments}

Formal instruments given to pupils and teachers are described in this part. The study made use of questionnaires, interviews, and personal observations.

\subsection{Findings and Discussions}

\section{Effects of Human Rights Violations on Students}

This section focuses on the effects of human rights violations on the students in the school. The findings are presented in the following Tables and Figures.

Table 1.0: Teachers general perception of effects of human rights on students

\begin{tabular}{lllllllll}
\hline Statement & $\begin{array}{l}\text { Strongly } \\
\text { Agree }\end{array}$ & & Agree & & \multicolumn{2}{c}{ Disagree } & $\begin{array}{l}\text { Strongly } \\
\text { disagree }\end{array}$ \\
& Freq & \% & Freq & \% & Freq & \% & Freq & \% \\
\hline Low self-esteem & 3 & 43 & 2 & 29 & 1 & 14 & 2 & 29 \\
Physical injuries from caning & 4 & 57 & 3 & 43 & 0 & 0 & 0 & 0 \\
Denial of religious rights & 6 & 86 & 1 & 14 & 0 & 0 & 0 & 0 \\
Behavioural impacts such as timidity & 2 & 29 & 3 & 43 & 1 & 14 & 1 & 14 \\
Academic drop-out & 4 & 57 & 3 & 43 & 0 & 0 & 0 & 0 \\
Pregnancy & 5 & 71 & 2 & 29 & 0 & 0 & 0 & 0 \\
Poor interpersonal relationship between students & 4 & 57 & 3 & 43 & 0 & 0 & 0 & 0 \\
and students & & & & & & & & \\
Depression & 6 & 86 & 1 & 14 & 0 & 0 & 0 & 0 \\
Self-harm & 3 & 43 & 4 & 57 & 0 & 0 & 0 & 0 \\
Hostility towards other people & 4 & 57 & 3 & 43 & 0 & 0 & 0 & 0 \\
Fear and an inability to express feelings & 3 & 43 & 3 & 43 & 1 & 0 & 1 & 0 \\
\hline
\end{tabular}

Table 4.6 shows that teachers point to several possible effects of human rights on students. Here, in terms of perception, all teachers (100\%) believed that human rights violations can lead to depression, self-harm and hostility towards others. Also, in terms of perception $86 \%$ representing 6 out of 7 teachers believed that human rights violations lead to fear and an inability to express feelings among students as well as timidity.

Plate 5: Statement about the psychological impact of human rights violations in school

You see we are human beings. A basic understanding of human rights is that it is part of what makes us human beings. This is why they say it is inalienable. This also means that if you are denied your rights you become a less than a human being. ... You cannot feel like a full human beings. You may think about yourself as someone who is inferior. ...it makes you timid and you may become very depressed. This will affect your self-esteem, our value as a human being. For children I think that can cause lots of psychological problems especially if the person is not from a home where she has love and care. This is why I think we need to be careful as teachers in the way we treat students (Teacher 4, Female teacher)

This teacher comment in Plate 5 indicates that he thinks human rights violations can have psychological impacts on students. The suggestion is that some teachers are consciously aware of the violent effects that human rights violations can cause to children. These teachers may become the entry points for promoting students' rights in school. Her suggestion is that human rights violations can have several effect psychological effects - depression, feeling of inferiority, timidity - on the students.

The students data has interesting dimensions too 
Table1 1;Students perception of effects of human rights violations in school

\begin{tabular}{lllllllll}
\hline Statement & $\begin{array}{l}\text { Strongly } \\
\text { Agree }\end{array}$ & & Agree & & Disagree & $\begin{array}{l}\text { Strongly } \\
\text { disagree }\end{array}$ \\
& Freq & \% & Freq & \% & Freq & \% & Freq & \% \\
\hline Low self-esteem & 35 & 80 & 9 & 20 & 0 & 0 & 0 & 0 \\
Denial of religious rights & 25 & 57 & 14 & 32 & 2 & 5 & 3 & 7 \\
Behavioural impacts such as timidity & 23 & 53 & 19 & 43 & 1 & 2 & 1 & 2 \\
Academic drop-out & 34 & 77 & 9 & 20 & 1 & 2 & 0 & 0 \\
Pregnancy & 32 & 73 & 5 & 11 & 5 & 11 & 2 & 5 \\
Poor interpersonal relationship between students & 24 & 55 & 19 & 43 & 1 & 2 & 0 & 0 \\
and students & & & & & & & & \\
Depression & 35 & 80 & 9 & 20 & 0 & 0 & 0 & 0 \\
Hostility towards other people & 25 & 57 & 14 & 32 & 2 & 5 & 3 & 7 \\
Fear and an inability to express feelings & 32 & 73 & 12 & 27 & 0 & 0 & 0 & 0 \\
\hline
\end{tabular}

The Table 4.7 shows that the students mainly highlight psychological and emotional issues. As the table shows, low self-esteem, depression, self-harm fear and inability to express feelings are issues that all students $(100 \%)$ either strongly agree or agree as effects of human rights abuses. This is followed by dropping out (97\%), timidity $(96 \%)$, hostility towards others $(89 \%)$ and denial of religious freedom $(89 \%)$. Pregnancy follows with $84 \%$. This again suggests that people look at human rights issues more from a relational aspect than just a given.

\subsection{Effects of human rights violations on the students}

This section discusses the effects of human rights violations on the students in the school. The fact that the effects mainly highlight denial of students' religious rights in school, low self-esteem and poor interpersonal relationship between teachers and students suggest the relational nature of human rights as suggested by discourse scholars (Dembour, 2010).

The data in Table 4.7 shows that human rights violations mainly have psychological and emotional effects including low self-esteem, depression and inability to express feelings as well as hostility towards others. This list highlights the points by Hamarus and Kaikkonen (2008) that the effects of human rights violations on children are mainly psychological and emotional torture. Also, the point about low self-esteem highlights that psychological effects may result from human rights violations in the school. Other effects include denial of religious freedom, pregnancy and dropping out of school. The fact that pregnancy is mentioned means implies that there are elements of sexual violations of female students. Alternatively it suggests that some human rights violations lead students to sexual misconduct. The case of sexual abuse is not the main subject of this research and so may be explored further.

The denial of religious freedom on the other hand suggests a violation of Chapter 5 of Ghana's 1992 Constitution which entrenches freedom of religion. The point about dropping out of school highlights assertions in the literature that intimidation, humiliation within schools may lead to children dropping out of school (Obeng, 2002; Akyeampong et al, 2007; Asamani, 2000; Pryor \& Ampiah, 2003; Owusu, 2009; Antonowicz, 2010; Alhassan \& Adzahlie-Mensah; 2010; Dunne, et al, 2010; Anaga, 2012).

Another problem with dropping out is the denial of students' rights to education as discussed by Tomaševski (2005) and Shumba (2003). This affects students' access to education as enshrined in the Universal Declaration of Human Rights (1948), the UN Declaration of the Rights of the Child (1959) and the Convention against Discrimination in Education (1962). This violation defeats the goals of the World Declaration on Education for All and the Dakar Framework for Action (1990) that: "Every person - child, youth and adult - shall be able to benefit from educational opportunities designed to meet their basic learning needs. This means that there is a need to take measures to actualise Article 28 of the Convention on the Rights of the Child (1989), which requires States to take measures to encourage regular attendance at schools and reduce drop-out rates.

\subsection{Conclusion}

Human rights violations affect the students in many ways - denial of rights such as the freedom to expression and the right to practice the religion of their choice, and mainly psychological, emotional torture and relational problems including fear of teachers, low self-esteem and poor interpersonal relationship between teachers and students. Other are denied the right to education when they drop out of school.

\subsection{Recommendations}

From the findings the following recommendations are made:

- There is need for clear legislation stating children's rights in school and educators and teachers responsibilities to protect, preserve and promote those rights.

- The Ministry of Education should push for the legislators to design appropriate disciplinary measures that 
can be taken when children's rights are violated.

- The Ghana Education Service should design systems to support students to seek redress when their rights are violated. This may include identifying teachers who could serve as human rights laisons in schools.

- It may be important for the Ghana education Service to develop a human rights barometer instrument that can be used to conduct annual school census which can be published to show the human friendly nature of each school.

- The National Commission on Civic Education and non-governmental organisations involved in child protection issues should help the Ghana Education Service to develop pre-service and in-service human right education programmers for teachers

- Child protection agencies such as UNICEF, the Ministry of Gender, Children and Social Protection, the Department of Social Welfare to work with the Ghana Education Service to develop safety nets for protecting children from further abuse when those children take action to seek redress because their rights have been violated.

- Human rights education should be carried in schools to education students on their rights and responsibilities in school.

- The Safe School for Girls campaign by UNICEF and other child protection organisations should continue to ensure that violence that girls suffer in education is addressed.

\section{REFERENCES}

Bandura, A. (1977). Peer involvement in abuses: insight and challenges for intervention Social learning theory. Englewood Cliffs, NJ. Prantice Hall.

Bell, J. (2004). Doing your research project: A guide for first time researchers for education and social sciences. Berkshire UK: Open University Press.

Convention on the Rights of the Child (CRC) adopted by the General Assembly on 20 November 1989, General Assembly Resolution 44/25.

Donkor, F. (1996). An assessment of the learning outcomes of environmental studies In senior schools of cape coast. Unpublished These, University of Cape Coast

Hazler, R. J. (2000). When victims turn aggressors. Philadelphia: Open University Press

ILO Convention no. 182 concerning Worst Forms of Child labour (Worst Form of Child Labour Convention, 1999), adopted June 17, 1999, entered into force Nov. 2000.

Lawrence, R. (1998). School crime and juvenile justice. New York: Oxford University Press

Nansel, T., Overpeck, M., Pilla, R., Ruan, W., Simon, M., \& Scheidt, P. (2001). Bullying behavior among US youth. Stanford: Standard University Press.

Olweus, D. (1991). Buyyly/Victim problems among schoolchildren. Hillsdal, N.J.: Erlbaum.

Reid, S. (1994). Working with statistics. Oxford: Polity Press.

Rigby, K. (2003). Consequences of human rights violations in school. Can J Psychiatry, Vol. 48, Say No to Abuse, Plan International Headquarters, UK, June 2002. 